\title{
COMPOSIÇÃO CORPORAL DE TAMBAQUI ALIMENTADO COM RAÇÕES CONTENDO FARINHA DE FOLHA DE LEUCENA
}

\author{
BODY COMPOSITION OF TAMBAQUI FED WITH DIETS CONTAINING \\ LEUCENA LEAVES MEAL \\ Pereira Junior, G. ${ }^{*}$; Barbosa, P.S.; Shimoda, E. e Pereira Filho, M.
}

\begin{abstract}
${ }^{1}$ Coordenação de Pesquisas em Aqüicultura. Instituto Nacional de Pesquisas da Amazônia. Petrópolis,
\end{abstract} Aleixo. Manaus, AM. Brasil. *geraldoinpa@hotmail.com

\section{PALAVRAS ChaVE ADICIONAIS \\ Colossoma. Nutrição. Peixe. Proteína.}

\section{RESUMO}

O objetivo deste trabalho foi avaliar os efeitos da inclusão de farinha de folha de leucena em dietas sobre a composição corporal de juvenis de tambaqui. Um total de 240 juvenis foram distribuídos em 12 caixas plásticas ( $350 \mathrm{~L}$ ), em um delineamento experimental inteiramente casualizado com quatro tratamentos $(0,8,16$ e $24 \%$ de inclusão de farinha de folha de leucena) e três repetições. Não houve diferença significativa $(p>0,05)$ entre os tratamentos, indicando que é possível incluir até $24 \%$ de farinha de folha de leucena em rações para juvenis de tambaqui, sem que haja alteração da composição corporal.

\section{SUMMARY}

The objective of this study was to evaluate the effects of inclusion of leucena leaf flour in diets on body composition of juveniles of tambaqui. A total of 240 juveniles were distributed in 12 plastic boxes ( $350 \mathrm{~L}$ ), in a completely randomized experimental design with four treatments $(0,8,16$ and $24 \%$ of inclusion of leucena leaf flour) and three replications. There was no significant difference $(p>0.05)$ between treatments, indicating that it can be possible to include up to $24 \%$ leucena leaf flour in diets for juveniles of tambaqui, with no change in body composition.

\section{INTRODUÇÃO}

O tambaqui Colossoma macropomum é um peixe endógeno da bacia amazônica,

\author{
AdDitionAL KEYWORDS \\ Colossoma. Fish. Nutrition. Protein.
}

sendo a $3^{\mathrm{a}}$ espécie de peixe mais cultivada no Brasil em 2007, representando mais do que $10 \%$ do total produzido (IBAMA, 2007). Dentre as vantagens do cultivo de tambaqui, pode ser destacado o bom potencial em aproveitar proteína de origem vegetal, sendo que frutas e sementes são os alimentos preferidos pelo tambaqui em ambiente natural(Araújo-Lima e Goulding, 1998). Também podem ser citados o rápido crescimento, a alta produtividade, a qualidade excelente da carne e o interesse pela esportividade na pesca (Fernandes et al., 2000). Apesar do bom desempenho zootécnico apresentado pelo tambaqui, os elevados custos com rações balanceadas podem diminuir a rentabilidade do piscicultor, sendo a proteína o nutriente mais caro da dieta. De acordo com Melo et al. (2001), a rentabilidade da produção de tambaqui em viveiros pode variar de 19 a $40 \%$.

Uma das fontes proteícas mais amplamente utilizadas no Brasil é a farinha de peixe, que é de alto custo, além de apresentar heterogeneidade na sua composição (Fernandes et al., 2000). Alguns trabalhos foram realizados com o intuito de substituir a farinha de peixe pelo farelo de soja para o pacu Piaractus mesopotamicus (Fernandes et al., 2000), pelo farelo de canola para 
curimbatá Prochilodus lineatus (Galdioli et al., 2002), por levedura de cana para o jundiá Rhamdia quelen (Piaia e Radünz Neto, 1997), dentre outros. Apesar de diversos ingredientes já terem sido testados em substituição à farinha de peixe, poucos ingredientes mostraram bons resultados, havendo alteração inclusive na composição corporal dos peixes (França-Segundo et al., 2006).

A leucena (Leucaena leucocephala) é uma leguminosa que poderia ser utilizada na alimentação do tambaqui, pois este peixe aproveita bem ingredientes de origem vegetal na ração. Outro fator que contribui para a possibilidade de utilização desta planta é a sua composição aproximada de $30 \%$ de PB, em termos de MS (Pires et al., 2001). Apesar de ser originária da América Central, a leucena apresenta alta disponibilidade em todo território brasileiro, inclusive na região amazônica (Cristina et al., 1999).

Potencialmente, poderia ser considerada a inclusão da farinha de folha de leucena na ração. Desta forma, o objetivo do presente trabalho foi verificar a influência de diferentes níveis de inclusão da farinha de folha de leucena em rações sobre a composição bromatológica de juvenis de tambaqui.

\section{MATERIALE MÉTODOS}

Este experimento foi conduzido, por um período de 60 dias, na Coordenação de Pesquisas em Aqüicultura/CPAQ, do Instituto Nacional de Pesquisas da Amazônia/ INPA, Manaus - AM.

Foram utilizados 250 juvenis de tambaqui, com peso médio inicial de $41,1 \pm 4,83 \mathrm{~g}$, provenientes dos estoques da CPAQ/INPA em um delineamento experimental inteiramente casualizado constituído de quatro tratamentos e três repetições. Cada unidade experimental foi representada por 20 indivíduos acondicionados em caixa plástica redonda com capacidade para $350 \mathrm{~L}$, abastecida com água de poço artesiano, aeração constante, renovação diária de água ( $10 \%$ do volume total) e monitoramento dos parâmetros físico-químicos da água. A cada sete dias foram realizadas, em todas as unidades experimentais, medidas de condutividade elétrica, amônia, nitrito, alcalinidade e dureza sendo utilizados um condutivímetro digital, o método do endofenol e colorimetria, respectivamente. Já as medidas de temperatura da água, oxigênio dissolvido (com oxímetro) e $\mathrm{pH}$ (medidor de $\mathrm{pH}$ digital de bancada) foram tomadas diariamente pela manhã (9h).

Foram formuladas quatro dietas experimentais isoprotéicas $(32 \% \mathrm{~PB})$ e isocalóricas (3500 kcal ED/kg) com níveis crescentes de inclusão de farinha de folha de leucena $(0,0$; 8,$0 ; 16,0$ e 24,0 \%). Para obtenção da farinha

Tabela I. Composição centesimal dos ingredientes utilizados na formulação das rações experimentais. (Proximate composition (\%) of ingredients used in the formulation of experimental diets).

\begin{tabular}{lcccccc}
\hline & MS & PB & EE & FB & ENN & Cinzas \\
\hline Farinha de peixe & 87,6 & 62,1 & 8,5 & - & - & 13,1 \\
Milho & 89,5 & 8,1 & 3,6 & 1,6 & 75,5 & 0,5 \\
Farelo de trigo & 90,2 & 16,0 & 3,4 & 4,8 & 61,1 & 4,6 \\
Farelo de glúten de milho & 91,2 & 39,4 & 0,4 & 0,6 & 48,1 & 2,0 \\
Óleo de soja & 100,0 & - & 10,0 & - & - & - \\
Farinha de folha de leucena & 90,3 & 21,0 & 3,5 & 12,0 & 48,6 & 6,1 \\
\hline
\end{tabular}

$\mathrm{MS}=$ Matéria seca; $\mathrm{PB}=$ proteína bruta; $\mathrm{EE}=$ extrato etéreo; $\mathrm{FB}=$ fibra bruta; $\mathrm{ENN}=$ extrativo não nitrogenado.

Archivos de zootecnia vol. 62, núm. 238, p. 212. 


\section{BROMATOLOGIA DE TAMBAQUI ALIMENTADO COM RAÇÕES CONTENDO LEUCENA}

de folha de leucena, foram coletadas folhas de plantas adultas, desidratadas em estufa com circulação forçada de $\operatorname{ar}\left(40^{\circ} \mathrm{C}\right.$, por 48 horas). Após a desidratação, os folíolos foram retirados e moídos em moedor de carne, com matriz fina de $6 \mathrm{~mm}$.

Os ingredientes utilizados na composição das rações foram analisados bromatologicamente antes da formulação (tabela I). Após pesagem, os ingredientes foram misturados, umedecidos e processados em moedor de carne, com matriz de $6 \mathrm{~mm}$, para a formação dos pellets. Para secagem destes, foi usada uma estufa com circulação forçada de ar, a temperatura constante de $30^{\circ} \mathrm{C}$. Após a elaboração das rações, foram coletadas amostras para determinação de suas composições centesimais (tabela II).

Para adaptação às condições experimentais, os peixes foram alimentados com uma dieta controle (comercial) contendo 32 $\%$ de proteína bruta, durante uma semana. Após esta fase, os animais foram submetidos a um jejum de 24 horas e, posteriormente, alimentados duas vezes ao dia (8:30 e 16:30 h) com a ração experimental, até a saciedade aparente.

Para medir os efeitos dos tratamentos sobre a composição corporal dos animais experimentais, amostras de juvenis de tambaqui foram escolhidas aleatoriamente no início $(n=10)$ e no final do experimento ( $n=3$ em cada unidade experimental), para determinação da umidade, proteína bruta, cinzas e extrato etéreo.

As análises da composição centesimal dos ingredientes, rações e peixes foram realizadas no Laboratório de Nutrição de Peixes/ CPAQ/INPA, segundo metodologia descrita pela AOAC (1997).

Para avaliar os efeitos dos tratamentos, foi usada a análise de variância (ANOVA) para os dados de proteína bruta. Por não terem atendido os pressupostos da ANOVA, foram submetidos ao teste de distribuição livre de Kruskal-Wallis ( $\mathrm{p}<0,05)$ os dados de matéria seca, cinzas e extrato etéreo.
Tabela II. Composição percentual e química das dietas experimentais com diferentes níveis de inclusão de farinha de folha de leucena. (Percentage composition and chemistry of experimental diets with different levels of inclusion of leucaena leaf meal).

\begin{tabular}{lcccc}
\hline & \multicolumn{4}{c}{ Farinha de folha (\%) } \\
& 0 & 8 & 16 & 24 \\
\hline Farinha de peixe \% & 36,0 & 33,0 & 31,0 & 28,0 \\
Milho \% & 27,0 & 43,0 & 40,0 & 30,0 \\
Farelo de trigo \% & 34,0 & 7,0 & 0,0 & 1,0 \\
Farelo glúten milho \% & 0,0 & 6,0 & 8,0 & 10,0 \\
Óleo de soja \% & 2,0 & 2,0 & 4,0 & 6,0 \\
Farinha folha leucena \% & 0,0 & 8,0 & 16,0 & 24,0 \\
Premix* & 1,0 & 1,0 & 1,0 & 1,0 \\
Total & 100 & 100 & 100 & 100 \\
Matéria seca (\%) & 92,5 & 91,5 & 91,7 & 91,6 \\
Proteína bruta (\%) & 30,5 & 32,8 & 33,1 & 35,3 \\
Extrato etéreo (\%) & 6,6 & 6,4 & 7,6 & 8,7 \\
Cinzas (\%) & 7,1 & 5,5 & 5,3 & 5,4 \\
Fibra bruta (\%) & 3,9 & 2,6 & 4,2 & 4,4 \\
ENN (\%) & 44,4 & 44,2 & 41,5 & 37,8 \\
EB (kcal/kg) & 4168 & 4270 & 4289 & 4364 \\
EB:PB & 13,6 & 13,0 & 12,95 & 12,3 \\
\hline
\end{tabular}

*Composição por kg ração: Vitamina A: 12000 UI; Vitamina B12: 40 mg; Vitamina D: 2000 UI; Ácido fólico: $5,0 \mathrm{mg}$; Ácido pantotênico: $60 \mathrm{mg}$; Vitamina B1: 20 mg; Vitamina B2: 40 mg; Vitamina B6: 120 mg; Vitamina K: $10 \mathrm{UI}$; Colina: 500 mg; Cobre: 0,3 ppm; Ferro: 7,5 ppm; lodo: 20 ppm; Manganês: 40 ppm; Zinco: 7 ppm.

$\mathrm{ENN}=$ extrativo não nitrogenado; $\mathrm{EB}=$ energia bruta; $\mathrm{PB}=$ proteína bruta.

\section{RESULTADOS}

Os valores médios para as variáveis físico-químicas da água não apresentaram diferenças estatísticas significativas $(p>0,05)$ entre os tratamentos.

Não foram encontradas diferenças significativas $(p>0,05)$ entre os tratamentos para a composição corporal dos animais experimentais (tabela III).

Para os teores de proteína bruta, observa-se que os peixes alimentados com dietas $0 \%$ folha, apresentaram maior valor numé- 
Tabela III. Percentual de umidade, proteína bruta, cinza e extrato etéreo no músculo dos tambaquis nos diferentes tratamentos (valores médios \pm desvio padrão). (Percentage of moisture, crude protein, ash and lipids in muscle of tambaquis fed different diets (mean values \pm standard deviation)).

\begin{tabular}{lcccc}
\hline & UM & PB & CZ & EE \\
\hline 0 \% folha & $72,8 \pm 1,0$ & $13,0 \pm 1,5$ & $2,8 \pm 0,7$ & $9,5 \pm 0,9$ \\
$8 \%$ folha & $72,8 \pm 0,7$ & $11,8 \pm 0,3$ & $2,5 \pm 0,3$ & $9,8 \pm 0,2$ \\
$16 \%$ folha & $72,3 \pm 1,0$ & $12,1 \pm 0,6$ & $2,9 \pm 0,0$ & $9,7 \pm 0,4$ \\
$24 \%$ folha & $72,7 \pm 1,3$ & $12,2 \pm 0,1$ & $2,8 \pm 5,4$ & $9,6 \pm 0,4$ \\
\hline
\end{tabular}

Inicial = Análise centesimal dos tambaquis no início do experimento.

$\mathrm{EE}=$ Extrato etéreo; $\mathrm{PB}=$ Proteína bruta; $\mathrm{UM}=$ Umidade; $\mathrm{CZ}=$ Cinzas.

rico para esta variável $(13,0 \pm 1,53)$, sendo seguidos pelas dietas $24 \%(12,2 \pm 0,1), 16 \%$ $(12,1 \pm 0,6)$ e $8 \%$ folha $(11,8 \pm 0,3)$, respectivamente.

Para o extrato etéreo, apesar de não haver diferença significativa $(p>0,05)$ entre os tratamentos, observa-se que os peixes alimentados com dietas contendo farinha de folha de leucena apresentaram maior deposição de gordura corporal, sendo o maior valor referente ao tratamento com $8 \%$ $(9,8 \pm 0,2), 16 \%(9,7 \pm 0,4)$ e $24 \%$ folha $(9,6$ $\pm 0,4$ ), respectivamente. Os peixes alimentados com a dieta $0 \%$ apresentaram o menor valor para o extrato etéreo $(9,5 \pm 0,9)$.

Para cinzas, também não houve diferenças significativas entre tratamentos, sendo que, numericamente, o maior valor foi observado nos peixes da dieta $16 \%(2,9 \pm$ $0,0)$ e o menor valor foi observado nos peixes da dieta $8 \%(2,5 \pm 0,3)$. Os peixes das dietas com 0 e $24 \%$ apresentaram valor semelhante para esta variável.

\section{DISCUSSÃO}

Os parâmetros físico-químicos da água (tabela IV) apresentaram-se dentro dos recomendados para o cultivo do tambaqui (Kubitza, 2003).

Apesar das rações terem sido formuladas para serem isoprotéicas e isocalóricas, foram verificadas diferenças na composição centesimal final das rações. Essas diferenças influenciaram na relação proteína:energia das rações e podem estar relacionadas com variações na composição centesimal dos ingredientes utilizados para elaborar as rações.

Mesmo não havendo diferença significativa entre os tratamentos, os peixes alimentados com a ração controle apresentaram maior teor de proteína corporal, quando comparados aos peixes dos demais

Tabela IV. Média e desvio-padrão dos parâmetros de qualidade da água durante o período experimental. (Mean and standard deviation of water quality parameters during the experimental period).

\begin{tabular}{lcccc}
\hline & \multicolumn{2}{c}{ Farinha de folha (\%) } \\
& 0 & 8 & 16 & 24 \\
\hline Oxigênio $(\mathrm{OD})(\mathrm{mg} / \mathrm{L})$ & & $5,7 \pm 0,2$ & $5,5 \pm 0,1$ & $6,0 \pm 0,4$ \\
Condutividade $\left(\mu \mathrm{S} . \mathrm{cm}^{-2}\right)$ & $23,3 \pm 0,6$ & $23,8 \pm 0,7$ & $23,5 \pm 0,5$ & $23,6 \pm 0,3$ \\
$\mathrm{pH}$ & $5,2 \pm 0,0$ & $5,3 \pm 0,0$ & $5,3 \pm 0,0$ & $5,2 \pm 0,0$ \\
{$\left[\mathrm{NH}_{3}\right]_{\text {total }}(\mathrm{mg} / \mathrm{L})$} & $0,3 \pm 0,0$ & $0,3 \pm 0,1$ & $0,3 \pm 0,0$ & $0,3 \pm 0,0$ \\
$\mathrm{Nitrito}(\mathrm{NO})(\mathrm{mg} / \mathrm{L})$ & $0,0 \pm 0,0$ & $0,1 \pm 0,0$ & $0,0 \pm 0,0$ & $0,0 \pm 0,0$ \\
Dureza $\left(\mathrm{mg} \mathrm{de} \mathrm{CaCO}_{3} / \mathrm{L}\right)$ & $3,7 \pm 0,0$ & $3,8 \pm 0,0$ & $3,7 \pm 0,0$ & $3,5 \pm 0,0$ \\
Alcalinidade $\left(\mathrm{mg} \mathrm{de} \mathrm{CaCO}_{3} / \mathrm{L}\right)$ & $5,2 \pm 0,0$ & $5,4 \pm 0,0$ & $5,1 \pm 0,0$ & $5,1 \pm 0,0$ \\
Temperatura $\left({ }^{\circ} \mathrm{C}\right)$ & $28,2 \pm 0,0$ & $28,2 \pm 0,0$ & $28,2 \pm 0,0$ & $28,0 \pm 0,0$ \\
\hline
\end{tabular}

Archivos de zootecnia vol. 62, núm. 238, p. 214. 


\section{BROMATOLOGIA DE TAMBAQUI ALIMENTADO COM RAÇÕES CONTENDO LEUCENA}

tratamentos. Vale ressaltar que a ração controle possui menor teor proteico $(30,5)$ do que as rações que receberam farinha de folha de leucena $(32,8$ - T2; 33, 1 - T3; 35,3 T4). Isso sugere que os juvenis de tambaqui aproveitaram a proteína da farinha de peixe de maneira mais eficiente do que a proteína da farinha de folha de leucena. Segundo Kohla et al. (1992), a farinha de peixe é um ingrediente com excelentes características nutricionais, sendo muito bem aproveitada pelos peixes. Entretanto, devem ser levados em consideração o custo elevado deste produto e sua baixa disponibilidade comercial (Rocha, 2004).

Os animais experimentais alimentados com dietas contendo farinha de folha de leucena apresentaram deposição de gordura corporal ligeiramente superior aos peixes do tratamento controle. Isso pode ser explicado pelos maiores níveis de inclusão de óleo nas dietas contendo farinha de folha de leucena, proporcionando maior teor energético nessas dietas. Resultado semelhante foi encontrado por Lanna et al. (2004) que avaliaram os efeitos de diferentes níveis de fibra bruta e de óleo na composição química da carcaça de tilápias, concluindo que a maior inclusão de óleo à ração tem efeito significativo no depósito de gordura corporal. Bairagi et al. (2004) e Chou et al. (2003), também observaram maior deposição de gordura corporal nos peixes alimentados

\section{BIBLIOGRAFIA}

AOAC. 1997. Official methods of analysis. $17^{\text {th }} \mathrm{Ed}$. Association of Official Analytical Chemists Int. Gaithersburg. USA.

Araújo-Lima, C. e Goulding, M. 1998. Os frutos do tambaqui: ecologia, conservação e cultivo na Amazonia. MCT-CNPQ. Brasília. 186 pp.

Bairagi, A.; Ghosh, K.S.; Sen, S.K. and Ray, A.K. 2004. Evaluation of the nutritive value of Leucaena leucocephala leaf meal, inoculated with fish intestinal bacteria Bacillus subtilis and Bacillus circulans in formulated diets for rohu, Labeo rohita (Hamilton) fingerlings. com rações maiores níveis de extrato etéreo, indicando direcionamento do extrato etéreo da dieta para uso como fonte energética.

Os resultados observados neste estudo sugerem que a farinha de folha de leucena é um ingrediente com potencial de utilização em rações comerciais para juvenis de tambaqui, já que não houve alteração na composição corporal dos animais. O bom aproveitamento deste ingrediente pelo tambaqui pode estar relacionado com a capacidade desta espécie aproveitar bem alimentos de origem vegetal. Entretanto, vale ressaltar que este estudo foi conduzido com ração peletizada, sendo que o padrão comercial de rações para peixes é a ração extrusada. Desta maneira, novos estudos devem ser conduzidos buscando avaliar os efeitos da utilização de farinha de folha de leucena em rações para juvenis de tambaqui.

\section{CONCLUSÃO}

A inclusão de até $40 \%$ de farinha de folha de leucena em rações para juvenis de tambaqui não compromete a composição corporal dos peixes.

\section{AGRADECIMENTOS}

Agradecemos a Professora Maria Marta Garcia de Assis Rangel pelo auxílio na elaboração do resumo em inglês e à FAPEAM pelo auxílio financeiro.

Aquacul Res, 35: 436-446.

Chou, R.L.; Her, B.Y.; Su, M.S. and Hwang, G. 2003. Substituting fish meal with soybean meal in diets of juvenile cobia Rachycentron canadum. Aquaculture, 17: 1-9.

Cristina, S.; Perez, J.G.A. e Fanti, S.C. 1999. Crescimento e resistência à seca de leucena em solo de cerrado. Pesqui Agropecu Bras, 34: 933-944.

Fernandes, J.B.K.; Carneiro, D.J. e Sakomura, N. K. 2000. Fontes e níveis de proteína bruta em dietas para alevinos de Pacu (Piaractus meso- 
potamicus). Rev Bras Zootecn, 29: 646-653. França-Segundo, L.F.; Araripe, M.N.B.A. e Lopes, J.B. 2006. Substituição do farelo de soja pelo feno de leucena na alimentação de alevinos de tilápia. Rev Cient Prod Anim, 8: 28-34.

Galdioli, E.M.; Hayashi, C.; Soares, C.M.; Valéria Furuya, R.B.e Faria, A.C.E.A. 2002. Substituição da proteína do farelo de soja pela proteína do farelo de canola em rações para alevinos de Curimbatá (Prochilodus lineatus V.). Rev Bras Zootecn, 31: 552-559.

IBAMA. 2007. Estatística da pesca 2005. Brasil. Grandes regiões e unidades da federação. 147 pp.

Kohla, U.; Saint-Paul, U.; Friebe, J.; Wernicke, D.; Hilbe, V.; Braum, E. and Gropp, J. 1992. Growth, digestive enzyme activities and hepatic glycogen leavels in juvenile Colossoma macropomum Cuvier from South America during feeding, starvation and refeeding. Aquacult Fish Manag, 23: 189-208.

Kubitza, F. 2003. Qualidade da água no cultivo de peixes e camarões. Acqua Supre Com. Suprim. Aqüicultura Ltda. Jundiaí. 229 pp.
Lanna, E.A.T.; Pezzato, L.E.; Furuya, W.M.; Vicentini, C.A.; Cecon, P.R. e Barros, M.M. 2004. Fibra bruta e óleo em dietas praticas para alevinos de tilápia do Nilo (Oreochromis niloticus). Rev Bras Zootecn, 33: 1-12.

Melo, L.A.S.; Izel, A.C.U. e Rodrigues, F.M. 2001. Criação de tambaqui (Colossoma macropomum) em viveiros de argila/barragens no Estado do Amazonas. Embrapa Amazônia Ocidental. Série Documentos. p. 30.

Piaia, R. e Radünz Neto, J. 1997. Efeito de níveis crescentes de levedura de álcool em rações contendo fígado bovino sobre a performance de larvas de jundiá Rhamdia quelen. Ciênc Rural, 27: 313-317.

Pires, N.M.; Prates, H.T.; Pereira-Filho, I.A.; Oliveira, R.S. e Faria, T.C.L. 2001. Atividade alelopática da leucena sobre espécies de plantas daninhas. Scient Agric, 58: 61-65.

Rocha, A.S. 2004. Substituição do farelo de soja por feno de leucena (Leucaena leucocephala) na alimentação de tilápias (Oreochromis niloticus). Monografia de graduação da Universidade Federal do Piauí. Brasil. 49 pp. 